\section{Correspondence}

\section{Personal Accounts of Clinical Depression}

DeAR SIR

We are editing a book of personal accounts by mental health professionals describing and reflecting upon their experience of coping with and getting through their own clinical depression- how they fared and what they feel they learned from the experience.

Contributions would be between 75/20 typed A4 pages, and would deal with the writers' observations and reflections upon the phenomena and circumstances of their illness; factors which may have facilitated survival; usefulness or otherwise of help received, whether formally or informally; and lessons learnt from the experience, both personally and professionally.

The essays could be signed, anonymous or written under a pseudonym at the contributor's discretion.

To date we have about five or six contributors, all psychologists, and we would like to aim at around twice this number, the remainder being members of the other relevant professions-psychiatry, psychiatric nursing, social work and occupational therapy. We would be interested to hear from individuals in any of these categories who might like to contribute to this unusual study.

Department of Psychology

Institute of Psychiatry

Denmark Hill

London SE5 8AF

\section{VICKY RIPPERE Psychologist \\ Ruth Williams Psychologist}

\section{Recruitment to Mental Handicap}

DeAR SIR

I would like to welcome the recommendations made by the Mental Deficiency Section to improve recruitment to the sub-specialty (Bulletin, April 1980, p 61).

However, Recommendation 2 (b) is unrealisticproposing that all trainees should have a six-month rotation to mental handicap. I have long advocated a six-month placement to mental handicap on the grounds that it is . almost impossible to make a shorter placement a meaningful experience. In a rotational scheme such as Leicester's this would mean that not all the trainees could rotate to mental handicap-an acceptable compromise in my view, since only a very small proportion will give any serious consideration to specializing in mental handicap.

A. HAuck

Glenfrith Hospital

Consultant in Mental Handicap

Leicester

\section{Problems and Deficiencies in Community Services}

Dear SiR,

I have been grateful to those colleagues who have sent me their views and personal experiences about special responsibilities for community work, following my recent letter in the Bulletin (April, p. 60).

The Working Party would also like to know about particular problems resulting from the relationship between psychiatric and other services, e.g. general practitioners, social services, volunteers and also about the main deficiencies in community services. It has to consider whether consultants with a specified community interest would be in a stronger position to deal with these problems than existing staff. I shall look forward to hearing from any colleagues who would like to give their views to the Working Party on this question.

\section{Hope Hospital,}

Hugh L. Freeman, Consultant Psychiatrist

\title{
Psychiatrists in Australasia
}

Dear Sir,

In the March issue of the Bulletin (p. 43) appears a letter from Dr. Couper-Smart about the position of the MRCPsych. as a qualification in Australia.

A substantial number of psychiatrists here (perhaps 20 per cent) do not hold the MRANZCP and most have no intention of ever doing so unless the College changes its attitudes to reciprocity. There is also some suggestion that the percentage in increasing, though factual information is hard to obtain.

The main problem in not having the MRANZCP is one of communication within the profession, but it is likely that there will be set up in the near future an AMA subgroup for psychiatry which will go a long way toward solving this. It should be realized that the MRCPsych is an adequate specialist qualification for private practice under the Acts concerned with Medical Benefits and that any moves to change this are likely to be unsuccessful, as opposition will come from areas other than the practitioners immediately concerned. Also in so far as training is concerned the policy may well prove untenable because of its obvious inequity.

\section{Darling Street. \\ Wollongong,}

Gordon R. W. DAvies

N.S. W. 2500 